\title{
Use of Loglinear Models to Investigate the Patterns of Association among Fitness Test Performances
}

\author{
Peter D. Hart ${ }^{1,2, *}$ \\ ${ }^{1}$ Health Promotion Program, Montana State University - Northern, Havre, MT 59501 \\ ${ }^{2}$ Kinesmetrics Lab, Montana State University - Northern, Havre, MT 59501 \\ *Corresponding author: peter.hart@msun.edu
}

Received August 02, 2018; Revised September 14, 2018; Accepted September 24, 2018

\begin{abstract}
Background: Physical fitness tests are often administered as a battery, allowing for several different fitness scores. Furthermore, fitness scores are generally considered outcome variables, with no one test causing the performance of another. Therefore, using loglinear models to examine the relationship between fitness test performances is appropriate. Methods: This study used data from a campus-based fitness study of college students. Four physical fitness measures were used in the analysis. Cardiorespiratory fitness (CRF) was assessed by a multi-stage running test $\left(\mathrm{VO}_{\max }, \mathrm{ml} / \mathrm{kg} / \mathrm{min}\right)$. Lower-body power was assessed by a countermovement vertical jump (VJ) test (inches). Muscular endurance was assessed by a maximal push-up (PU) test (repetitions). Muscular strength was assessed by a 1RM bench press (BP) test. Participants were categorized into high or low fitness groups using each sex-specific fitness score median. Results: Results of the initial hierarchical loglinear models indicated no significant four-way or three-way interactions. A simplified loglinear model with all two-factor interactions provided adequate fit to the data. The odds of high $\mathrm{BP}$ performance were much greater with high $\mathrm{PU}(\mathrm{OR}=3.2)$ and $\mathrm{VJ}(\mathrm{OR}=2.3)$ performance. The odds of high CRF performance were also greater with high $\mathrm{PU}(\mathrm{OR}=2.4)$ and VJ $(\mathrm{OR}=2.7)$ performance. Finally, odds of high PU performance were much greater with high VJ $(\mathrm{OR}=3.6)$ performance. CRF and BP were statistically independent. Conclusion: Results from this study indicate that the performance on a fitness test can be related to at least one other fitness test performance.
\end{abstract}

Keywords: physical fitness, loglinear models, human performance, mosaic plot

Cite This Article: Peter D. Hart, "Use of Loglinear Models to Investigate the Patterns of Association among Fitness Test Performances.” American Journal of Sports Science and Medicine, vol. 6, no. 3 (2018): 84-88. doi: 10.12691/ajssm-6-3-4.

\section{Introduction}

Many physical fitness tests are administered as a collective group and produce several performance measures on specific populations, such as adults [1,2], elderly [3,4], children [5,6], military [7,8], and officers [9,10]. Physical fitness is a set of attributes that relate to one's ability to perform physical tasks [11]. These fitness attributes are often divided into five health-related components or six skill-related components [12]. Health-related fitness components are (1) cardiorespiratory endurance, (2) muscular strength, (3) muscular endurance, (4) body composition, and (5) flexibility. Whereas skill-related components are (1) agility, (2) balance, (3) coordination, (4) power, (5) speed, and (6) reaction time.

It is generally agreed that in order to increase an individual's fitness performance, a training program should be designed for that individual using the principles of specificity and overload [13]. It is also generally agreed that performance on a single fitness test is caused by an individual's natural ability and physical training [14] and is not caused by the performance of another fitness test.
Thus, fitness test performances can all be considered outcome variables, with no single test performance causing the performance of another. However, understanding the associations among fitness test performances can still be useful in both practice and research. Given this background, a statistical model that analyzes a set of variables without regard to their ability to predict could be useful for investigating the relationship among fitness test performances. Therefore, the purpose of this study was to employ loglinear models to examine the associations among a set of physical fitness test performances.

\section{Methods}

\subsection{Participants and Design}

Data for this research came from a cross-sectional fitness assessment study where $\mathrm{N}=87$ male and $\mathrm{N}=44$ female college students attending a rural public university volunteered to participate [15]. Students were recruited by campus flyers and word-of-mouth and offered free fitness evaluation in exchange for their participation. Study components and protocols were reviewed and approved by 
the university system's institutional review board (IRB).

\subsection{Variables Utilized}

The main outcome variables used in this research were cardiorespiratory fitness (CRF), vertical jump (VJ) height, maximal push-up (PU) repetition, and 1RM bench press (BP) load.

\subsection{Assessment of Fitness Tests}

CRF was assessed by a multi-stage running test, where participants continually ran a 20 meter distance within a period bound by starting and ending audio beeps [16]. The CRF test was stopped when the participant failed to reach the 20 meter mark before the ending beep twice in a row. The number of shuttles and levels completed were converted to maximal oxygen consumption (VO2max, $\mathrm{ml} / \mathrm{kg} / \mathrm{min})$. Lower-body power was assessed by a countermovement VJ test, where participants jump forcefully next to a wall and with dominant hand up and marking the wall with chalked fingers [17]. VJ scores were computed as the differences (inches) between participant jump height and pre-determined reach. Muscular endurance was assessed by a maximal PU test according to ACSM guidelines [18]. PU scores were computed as the total number repetitions (repetitions) completed with proper form. Muscular strength was assessed by a 1RM BP test according to ACSM guidelines [19]. The heaviest load (pounds) successfully lifted by the participant was recorded as their 1RM BP score.

\subsection{Statistical Analyses}

Descriptive statistics were computed for all study variables, both overall and by sex. Sex-specific median fitness scores were used to create four new dichotomous (high/ow) fitness performance measures. Hierarchical loglinear models were run by first examining the saturated four-factor $(2 \times 2 \times 2 \times 2)$ model and examining the four-way interaction. The next series of loglinear models concerned testing the fit with the three-way and then two-way interactions. Both the specific interaction tests as well as the model likelihood ratio $\left(G^{2}\right)$ statistics were used to determine model fit. Odds ratios (ORs) were computed using the loglinear estimates in the following way: $\exp (4 \times$ estimate $)$. To aid in OR interpretation, negative model estimates resulting in an $\mathrm{OR}<1.00$ were inverted. Mosaic plots were constructed to examine the four-way loglinear predicted value distribution. Finally, a multiple correspondence analysis (MCA) was conducted as an alternative procedure to examine and display the relationships among the fitness performance variables. All analyses were performed using SAS version 9.4 [20,21]. All p-values are reported as 2-sided and statistical significance was defined as $p$-values $<0.05$.

\section{Results}

Table 1 contains descriptive statistics of all study variables, overall and by sex. Males had significantly $(p s<.05)$ higher mean scores than females for CRF (36.9 vs. 30.6 $\mathrm{ml} / \mathrm{kg} / \mathrm{min}$ ), VJ (23.5 vs. 15.2 inches), PU (35.4 vs. 26.3 repetitions), and BP (232.0 vs. 95.6 pounds). Median fitness scores used to create dichotomous (high/low) fitness groups are also presented. Table 2 contains results from the simplest best fitting loglinear model. A four-way cross-classification loglinear model with only two-way interactions provided the best fit to the sample data $\left(G^{2}=\right.$ $5.29, p=.382)$. All two-way interactions were significant ( $p$ s $<.05$ ), except for $\mathrm{CRF}^{*} \mathrm{BP}$ (Wald $\chi 2=0.01, p=.918$ ). The $G^{2}$ statistic was not improved with $\mathrm{CRF}^{*} \mathrm{BP}$ omitted and therefore was left in the model.

Table 1. Descriptive statistics of study variables

\begin{tabular}{cccccc}
\hline Variable & Mean & Median & SD & Min & Max \\
\hline Overall & & & & & \\
CRF & 34.8 & 34.8 & 8.3 & 18.1 & 57.5 \\
VJ & 20.7 & 21.0 & 5.7 & 6.0 & 36.5 \\
PU & 32.3 & 30.0 & 15.1 & 2.0 & 83.0 \\
BP & 186.2 & 185.0 & 85.9 & 31.5 & 450.0 \\
& & & & & \\
Males & & & & & \\
CRF & 36.9 & 35.8 & 8.1 & 20.2 & 57.5 \\
VJ & 23.5 & 23.5 & 4.4 & 13.0 & 36.5 \\
PU & 35.4 & 32.0 & 16.0 & 8.0 & 83.0 \\
BP & 232.0 & 225.0 & 67.4 & 31.5 & 450.0 \\
& & & & & \\
Females & & & & & \\
CRF & 30.6 & 30.3 & 7.4 & 18.1 & 47.3 \\
VJ & 15.2 & 16.0 & 3.7 & 6.0 & 23.5 \\
PU & 26.2 & 25.0 & 11.1 & 2.0 & 45.0 \\
BP & 95.6 & 95.0 & 23.6 & 45.0 & 155.0 \\
\hline
\end{tabular}

Note. CRF is cardiorespiratory fitness in $\mathrm{ml} / \mathrm{kg} / \mathrm{min}$. VJ is counter movement vertical jump in inches. PU is maximal push-up test in repetitions. BP is $1 \mathrm{RM}$ bench press in pounds. Males had significantly $(p<.05)$ higher scores than females on all fitness variables.

Table 2. Loglinear analysis of four-way cross-classification fitness data

\begin{tabular}{|c|c|c|c|c|c|c|c|c|}
\hline Parameter & Group & Group & Estimate & $S E$ & $\chi^{2}$ & $p$ & OR & $O R^{\prime}$ \\
\hline Intercept & & & 1.8952 & 0.1037 & 333.88 & $<.001$ & & \\
\hline CRF & Low & & 0.0266 & 0.0941 & 0.08 & .778 & & \\
\hline VJ & Low & & -0.0325 & 0.1000 & 0.11 & .745 & & \\
\hline PU & High & & -0.0506 & 0.1013 & 0.25 & .617 & & \\
\hline BP & Low & & -0.0648 & 0.0951 & 0.46 & .495 & & \\
\hline $\mathrm{BP} * \mathrm{PU}$ & Low & High & -0.2908 & 0.1021 & 8.12 & .004 & 0.31 & 3.20 \\
\hline $\mathrm{BP}^{*} \mathrm{VJ}$ & Low & Low & 0.2086 & 0.1024 & 4.15 & .042 & 2.30 & 0.43 \\
\hline $\mathrm{CRF}^{*} \mathrm{PU}$ & Low & High & -0.2220 & 0.1027 & 4.67 & .031 & 0.41 & 2.43 \\
\hline PU*VJ & High & Low & -0.3204 & 0.1034 & 9.61 & .002 & 0.28 & 3.60 \\
\hline $\mathrm{CRF}^{*} \mathrm{VJ}$ & Low & Low & 0.2489 & 0.1009 & 6.09 & .014 & 2.71 & 0.37 \\
\hline $\mathrm{CRF}^{*} \mathrm{BP}$ & Low & Low & -0.0104 & 0.1016 & 0.01 & .918 & 0.96 & 1.04 \\
\hline
\end{tabular}

Note. CRF is cardiorespiratory fitness in $\mathrm{ml} / \mathrm{kg} / \mathrm{min}$. VJ is counter movement vertical jump in inches. PU is maximal push-up test in repetitions. BP is $1 \mathrm{RM}$ bench press in pounds. Group represents fitness classification. Final model provided adequate fit $G^{2}=5.29$, p $=.382$. The $G^{2}$ statistic was not improved with CRF*BP omitted. $\chi 2$ is Wald chi-square test. $O R$ is odds ratio. $O R^{\prime}$ is the $O R$ inverse for easier interpretation. A series of hierarchical loglinear models indicated no significant $(p<.05)$ four-way or three-way interactions. 


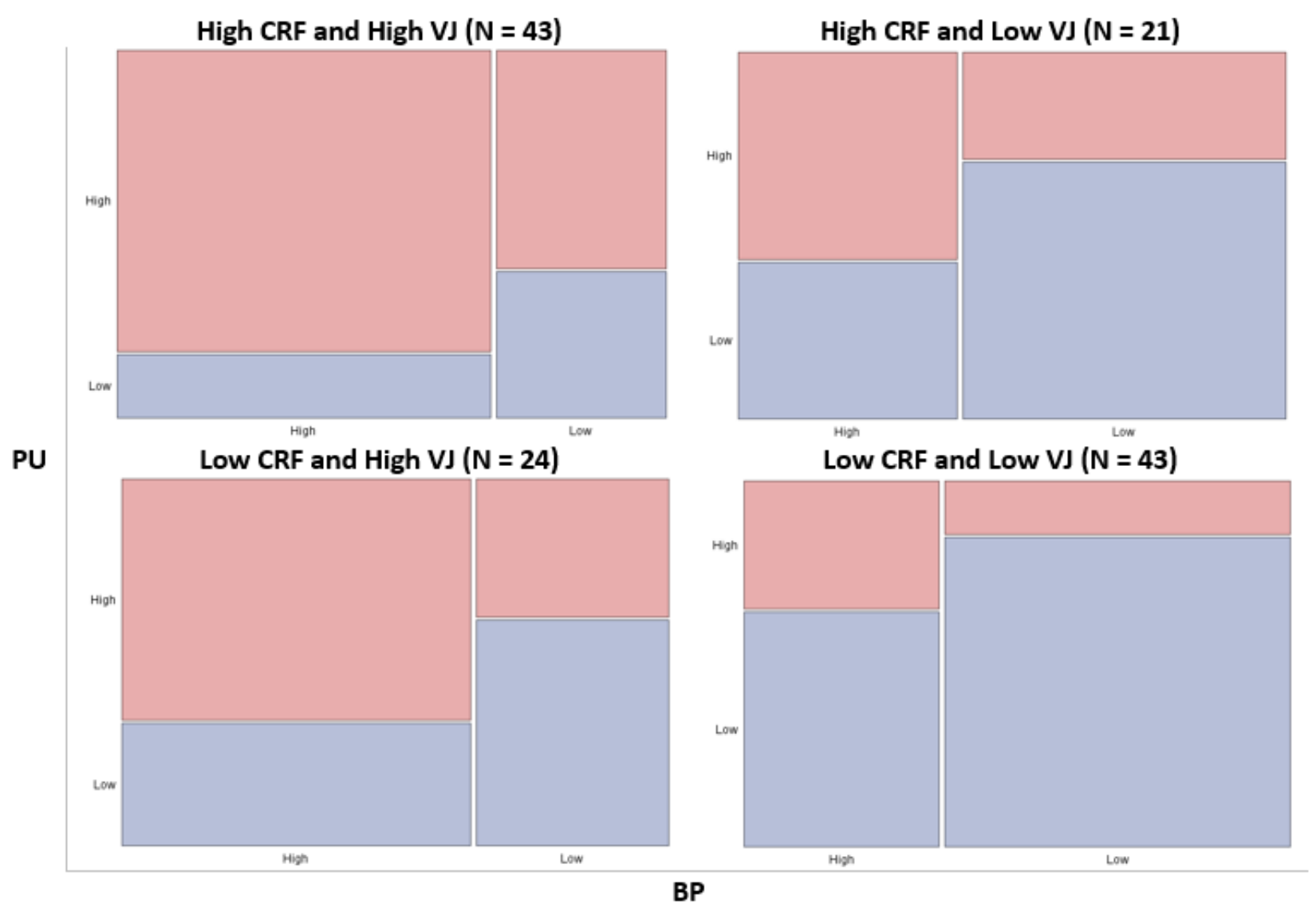

Figure 1. Mosaic plots of the four-way loglinear model predicted fitness frequencies (Note. Vertical axis represents PU fitness classification. Horizontal axis represents BP fitness classification. Each of the four plots represent a different CRF and VJ fitness classification.)

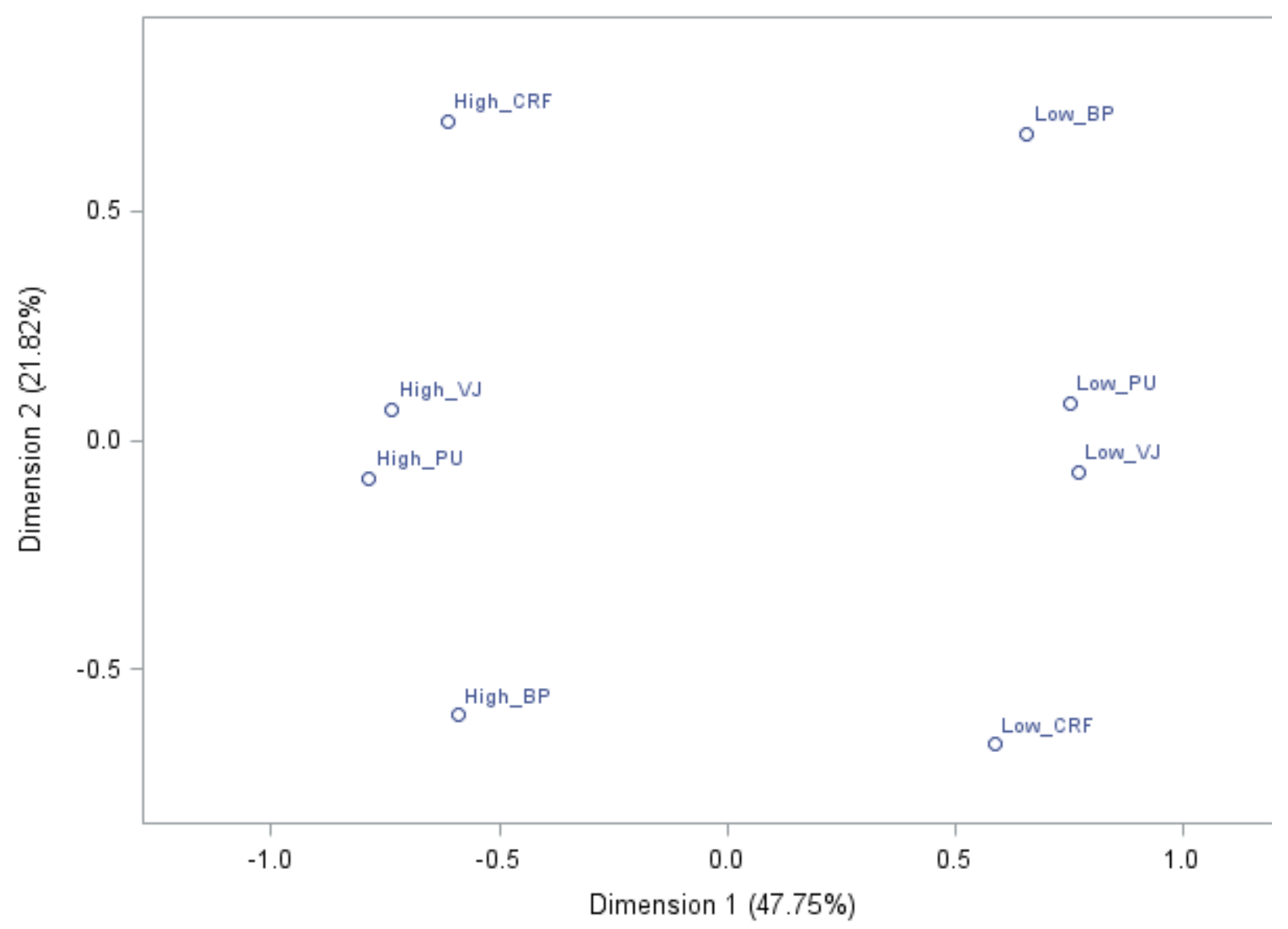

Figure 2. Multiple correspondence analysis (MCA) plot of first two dimensions relating all fitness categories (Note. MCA resulted in 70\% explained variance from the first two dimensions.) 
Results from the fitted loglinear model showed that the odds of high BP performance were much greater for those with high $\mathrm{PU}(\mathrm{OR}=3.2)$ and high VJ $(\mathrm{OR}=2.3)$ performance. Additionally, the odds of high CRF performance were greater for those with high $\mathrm{PU}(\mathrm{OR}=2.4)$ and high VJ $(\mathrm{OR}=2.7)$ performance. Finally, odds of high PU performance were much greater for those with high VJ $(\mathrm{OR}=3.6)$ performance. Figure 1 displays the distribution of predicted frequencies produced from the four-way loglinear analysis. It is apparent, for example, that individuals performing high on PU are more likely to have performed high on VJ (top red blocks, left vs. right). For another example, individuals performing high on BP are more likely to have performed high on PU (left blocks, top vs. bottom). Figure 2 displays the first two dimensions from the MCA plotted against each other. The first two dimensions explained a total of $70 \%$ of the variance in fitness performance. Similar to the loglinear analysis results, the MCA results showed strong relationships between pairs of fitness performance variables. For example, high PU and high BP were associated (bottom left quadrant). Additionally, high CRF and high VJ were associated (upper left quadrant). Although high PU is in the bottom left quadrant, it is close in proximity to the upper right quadrant - thus, it too is associated with high CRF. Also noteworthy, is the separation between CRF and BP.

\section{Discussion}

The purpose of this study was to examine the associations among four different physical fitness performance measures, without regard to causation. Loglinear models were used in a novel way to show that measures of cardiorespiratory endurance, lower body power, muscular endurance, and muscular strength are in fact related to one another. Furthermore, the loglinear analysis showed that only pairs of fitness performance measures interacted with each other. Said differently, no pair of fitness variables had different associations across any third or fourth fitness variable. Therefore, generalizations used in any two-way comparison can be considered valid.

The current study does have limitations worth noting. The most significant limitation is its cross-sectional design. Cross-sectional designs are a result of collecting data at one point in time [22]. Thus, associations reported from this study should not be interpreted as cause-and-effect. That is, it is not correct to infer that changing a college student's fitness performance on one test will change their performance on any other fitness test. It is suggested, that an experimental research design be implemented, in order to study such cause-and-effect associations. An additional limitation is this study's use of field tests to measure physical fitness performance. Although field tests are less accurate in measuring each physical fitness trait and possibly suffer from greater measurement error, lab testing of four different fitness traits on a large sample was impractical in this scenario.

\section{Conclusions}

Results from this study indicate that the performance on either a cardiorespiratory, lower body power, muscular endurance or muscular strength test is associated with at least one other test performance. The only pair of fitness outcomes not related were tests of cardiorespiratory endurance and muscular strength. Researchers and practitioners should be aware of these fitness-related associations among college students.

\section{Acknowledgements}

No financial assistance was used to assist with this project.

\section{References}

[1] Oja, P., \& Tuxworth, B. (Eds.). (1995). Eurofit for adults: Assessment of health-related fitness. Council of Europe.

[2] Suni, J., Husu, P., \& Rinne, M. (2009). Fitness for health: the ALPHA-FIT test battery for adults aged 18-69. Tester's Manual. Tampare, Finland: Published by European Union DS, and the UKK Institute for Health Promotion Research.

[3] Lemmink, K. A., Han, K., de Greef, M. H., Rispens, P., \& Stevens, M. (2001). Reliability of the Groningen fitness test for the elderly. Journal of Aging and Physical Activity, 9(2), 194-212.

[4] Rikli, R. E., \& Jones, C. J. (1999). Development and validation of a functional fitness test for community-residing older adults. Journal of aging and physical activity, 7(2), 129-161.

[5] Eurofit, C. O. E. (1993). Handbook for the Eurofit test on physical fitness. Strasbourg: Council of Europe.

[6] Welk, G., \& Meredith, M. D. (Eds.). (2010). Fitnessgram and activitygram test administration manual-updated 4th edition. Human Kinetics.

[7] Knapik, J. (1989). The Army Physical Fitness Test (APFT): a review of the literature. Military medicine, 154(6), 326-329.

[8] Bohnker, B. K., Sack, D. M., Wedierhold, L., \& Malakooti, M. (2005). Navy physical readiness test scores and body mass index (spring 2002 cycle). Military medicine, 170(10), 851-854.

[9] Rhodes, E. C., \& Farenholtz, D. W. (1992). Police Officer's Physical Abilities Test compared to measures of physical fitness. Canadian journal of sport sciences, 17(3), 228-233.

[10] U.S. Customs and Border Protection. (2015). Border Patrol Agent Pre-employment Fitness Test-1 Physical Readiness Program, U.S. DHS.

[11] American College of Sports Medicine, editor. ACSM's healthrelated physical fitness assessment manual. Lippincott Williams \& Wilkins. 2013.

[12] Nindl, B. C., Alvar, B. A., Dudley, J. R., Favre, M. W., Martin, G. J., Sharp, M. A., ... \& Kraemer, W. J. (2015). Executive summary from The National strength and conditioning association's second blue ribbon panel on military physical readiness: military physical performance testing. The Journal of Strength \& Conditioning Research, 29, S216-S220.

[13] American College of Sports Medicine. ACSM's Resources for the Exercise Physiologist, 2nd. Philadelphia, Md.: Lippincott Williams \& Wilkins. 2017.

[14] Raven P, Wasserman D, Squires W, Murray T. Exercise Physiology. Nelson Education. 2012.

[15] Hart, P. D., Benavidez, G., Detomasi, N., Potter, A. Rech, K., Budak, C., Faupel, N., Thompson, J., Schwenke, L., Jericoff, G., Manuel, M., Lee, T., Edmonson, W., Auzenne, C., Kirkaldie, T., Lonebear, M., \& Miller, L. (2017). A multitrait-multimethod (MTMM) study of fitness assessments in college students. SM Journal of Sports Medicine and Therapy. 1(1): 1002.

[16] Ramsbottom R, Brewer J, Williams C. A Progressive Shuttle Run Test to Estimate Maximal Oxygen Uptake. Br Sports Med. 1988; 22: $141-144$.

[17] Haff, G. G., \& Triplett, N. T. (Eds.). (2015). Essentials of strength training and conditioning 4th edition. Human kinetics.

[18] American College of Sports Medicine. (2018). ACSM's guidelines for exercise testing and prescription. Lippincott Williams \& Wilkins. 
[19] American College of Sports Medicine. (2012). ACSM's resource manual for guidelines for exercise testing and prescription. Lippincott Williams \& Wilkins.

[20] Stokes, M. E., Davis, C. S., \& Koch, G. G. (2012). Categorical data analysis using SAS. SAS institute.
[21] Cody, R. P., \& Smith, J. K. (2006). Applied Statistics \& SAS Programming. Prentice Hall.

[22] Matthews, T. D., \& Kostelis, K. T. (2011). Designing and conducting research in health and human performance. John Wiley \& Sons. 